He, K. (2013). He, K. (2013). Handbook of Research on Educational Communications and Technology (3rd Ed), some reflections (1): on a deeper understanding of the constructivist learning principles and constructivist instructional design. Journal of Educational Technology Development and Exchange, 6(2), 1-12

Handbook of Research on Educational Communications and Technology $\left(3^{\text {rd }}\right.$ Ed) Some Reflections (1):

\title{
On a Deeper Understanding of the Constructivist Learning Principles and Constructivist Instructional Design
}

\author{
Kekang He \\ Education Information Technology Synergy Innovation Center \\ Beijing Normal University
}

\begin{abstract}
Compiled by the Association of Educational Communications and Technology (AECT) in the US, the Handbook of Research on Educational Communications and Technology has impacted the field of educational technology in many important ways, since the 1990s. The third edition, published in 2008, in particular, provides the reader with more innovative content due to the collected efforts of its co-editors and a large team of contributing scholars. This article will focus on the third edition of the handbook by first outlining its overall structure and contents, and directing the reader to those arguments that stimulate the field most. It will then concentrate on a more in-depth discussion of a re-appraisal of the following two issues: the constructivist learning principles and the relationship between constructivist and engineering instructional design. The former is considered, in the third edition, as one of the two most important research discoveries, while the later is deemed as one of the four important developments in educational communications and technology in the past five years.
\end{abstract}

Keywords: Association for Educational Communications and Technology (AECT), Constructivist learning principles, Constructivist instructional design, engineering instructional design, minimally guided instruction, discovery learning

\section{Introduction}

Since the 1990s, the Association of Educational Communications and Technology (AECT) in the United States (US) has mobilized scholars in the field for the compilation and publication of the Handbook of Research on Educational Communications and Technology (hereafter the Handbook). This handbook has generated significant global impact on the field of educational technology. The third edition is the latest edition. The first two editions, published in 1996 and 2004 respectively, were both edited by David
Jonassen who was a professor at Columbia University in the US and a contemporary representative of radical constructivism. The third edition was launched in 2008 and edited by a group of well-established scholars in the field, consisting of J. Michael Spector, M. David Merrill, Jeroen van Merrienboer, and Marcy P. Driscoll.

There are 42 chapters in seven major parts in the first edition (Jonassen, 1996): (a) Foundations for Research in Educational Communications and Technology; (b) Hard Technologies: Media-related Research; 
(c). Soft Technologies: Instructional and informational Design Research; (d) Instructional Message Design Research; (e) Instructional Strategies Research; (f) Issues of Organization and Change in Educational Communications Technology; and (g) Research Methodologies in Educational Communications and Technology.

The second edition retains the structure and overall framework of the first edition (Jonassen, 2004). It only revised and updated the content of each chapter to reflect the new developments in the theory and practice of educational technology since the first edition, focusing on the developments made at the start of the $21^{\text {st }}$ century.

The third edition was significantly transformed. The Handbook was redesigned to include 56 chapters in six major parts relating to (a) foundations, (b) strategies, (c) technologies, (d) models, (e) design and development, and (f) methodological issues (Spector, Merrill, Jeroen \& Marcy, 2008). In addition, the book was edited by four co-editors instead of one. Each of the four co-editors was in charge of one part and supported by another co-editor and a team of editorial members. There is also a change in the composition of editorial members between the third edition and the first and second editions. All authors in the first and second editions were well-known experts and scholars in the US, while most of the chapters in the third edition were collaborative contributions of much acclaimed experts and scholars in the field, as well as young scholars who were not well known at the time. Furthermore, $20 \%$ of the authors and one co-editor in the third edition were not from the US. Precisely because of this change in its team of authors, the third edition, in contrast to the first and second, appears to be refreshingly open, international, and diverse in perspective. It also predicts the future developments of educational technology. What is worth mentioning here is the publication of the Chinese translation of over one million words Handbook in September 2012 after five years of collective efforts from a translation team led by Ren Youqun, Jiao Jianli, Liu Meifeng, and Wang Qiong.

\section{The Overall Framework and Key Contents of the Handbook $\left(3^{\text {rd }}\right.$ Ed)}

The third edition of the Handbook comprises six major parts: (1) foundations, (2) strategies, (3) technologies, (4) models, (5) design and development, and (6) methodological issues. The four parts from Part II to Part V (i.e., strategies, technologies, models, design and development) each outlines and discusses the historical development, research evolution, new developments, and future trends of its own research theme. These four parts focus on the use of information and communications technology to support teaching and learning, therefore forming the core contents of the Handbook. Part I, foundations, and Part VI, methodological issues, concentrate on research foundations and methodology, promoting a deeper understanding of the theoretical foundations, relevant hypotheses, and methodological issues in this field. These two parts provide useful guidance to the reader on the effective application of educational communications technology in practice.

Six review articles on the third edition of the Handbook were written by the translation team headed by Ren Youqun, Jiao Jianli, Liu Meifeng, and Wang Qiong, and were published in volumes 1-6 of China's Journal of Distance Education in 2010 (Zheng \& Ren, 2010; Wang, 2010; Zhao, 2010; Jiao, He \& 
Zhan, 2010; Kang, Ma, Ju \& Liu, 2010; Jiao, Zhan \& He, 2010). These articles discuss and analyse the contents of the six parts in detail. To help the reader understand the key points of the Handbook accurately, the contents of the six parts will be outlined below.

Part I, foundations, covers three main themes (Ren, Jiao, Liu \& Wang, 2011; Zheng \& Ren, 2010): historical foundations, theoretical foundations, and authentic learning related theoretical positions. The "historical foundations" section reviews milestone events and paradigm shifts in the history of educational communications technology. The "theoretical foundations" covers the theoretical foundations for research in educational communications and technology such as the psychology of learning and its philosophical foundation, empirical perspectives on memory and motivation, communications theory, human-computer interaction, and instructional design and development. When discussing authentic learning theories, the handbook addressed complexity theory, experiential, and situativity theory. This section ends with a brief discussion of the characteristics of the research foundations in educational communications technology.

Part II, strategies, also includes three main themes (Ren, Jiao, Liu \& Wang, 2011; Wang, 2010): learning theories, teaching models and instructional design principles in educational communications and technology. In terms of "learning theories," the Handbook focuses its review on technology-supported learning psychology and generative learning theories.

The section on "teaching" models outlines nine currently prevalent empirical models that have impacted teaching significantly. It also discusses the four focal points in technologysupported inquiry learning. When discussing instructional design principles in educational communications and technology, it introduces first principles of instructional design and the prescriptive principles for knowledge formation and teaching feedback.

Part III of the Handbook, technology, consists of four themes. First, while introducing the 16 chapters in this part, it also traces the developmental stages of different technologies by exploring their research development and future trends. Second, through a comparison with the contents in the technology part in the second edition, the third edition also captures the extension and changes in the themes of technology research. Third, from the perspectives of "hard technology," "soft technology," and "design technology," it evaluates the development of educational technology. Finally, it illustrates that the key feature of the development of contemporary educational technology is the further blending of teaching and information technology.

Part IV of the Handbook, models, is also composed of four themes. First, human cognitive architecture and technologybased teaching are examined that outlines the basis for human cognitive evolution and various instructional principles generated by cognitive load theory. Second, the nine general models directed toward learning in and outside schools are addressed that analyse the nine general models in educational communications and technology. Third, the application of models focusing on learning in specific domains discusses the application of various learning models to five disciplinary areas such as reading, mathematics, science, law and medicine. Finally, the summary, discussion, and outlook are presented that summarizes cognitive psychology-based models and the relationship between these 
models and explores the future applications of these models in different domains.

Part V of the Handbook, design and development, pertains to four areas of discussion. First, the chapter titled "Competencies for the New-Age Instructional Designer" points out the challenges facing new-age instructional designers, followed by the "Design and Development of Research Content and Practice" that introduces cognitive task analysis, tools for design and development of online instruction, design language, user-centred design and development, artefacts as tools in the design process, and the social consequences of design and development teams. Third, the evaluation reviews examine evaluation models and methodologies and discusses in detail the validation of technology-based performance assessments. Finally, the systems design for change in education and training illustrates the responsibilities of change agents, and introduces current research on systems design for systematic change in the fields of education and training.

Part VI of the Handbook, methodological issues in educational communications and technology, also has four components. First, research and theory development systematically discusses the four perspectives relating to theoretical statements, two theories, and the theory developments in educational communications and technology. Second, research approaches and four research designs analyses instructional strategies, educational technologies, instructional design models, and instructional design and development. This is followed by data collection and analysis that discusses methods of data collection and analysis for evaluating learning process and complex performance. Finally, a review and outlook of research summarizes the most significant developments and research findings in educational communications and technology in the last five years, and explores the possible development and the most significant research issues in the next five years in the field. This section also discusses, summarizes, and forecasts research methodologies in educational communications and technology.

\section{What are the Most Stimulating Discussions in the Handbook $\left(3^{\text {rd }} \mathrm{Ed}\right)$}

After careful reading of the translated third edition of the Handbook and reflecting on years of research and practice in educational communications and technology, the author has been provided with much insight into the significance of the Handbook. The author believes that the following five issues discussed in the Handbook are most the impressive and thought-provoking:

1. Constructivist learning principles and constructivist instructional design.

2. Complexity theory and technologysupported complex learning.

3. Situativity theory and situativity instructional model and strategies.

4. First principles of instruction and the four-component instructional design model (4C/ID model).

5. The arguments concerning the future of educational technology that are triggered by changes in the trends of the technology research.

In relation to the first issue, "the limitations of constructivist learning principles" is considered by the Handbook to be one of the two most important research findings in educational communications and technology in the last five years. The other most important finding relates to a deeper 
understanding of expertise reversal effect as one can see in Chapter 56, Foundations for the Future. Closely related to this issue is the "significant reduction in the gap and tension between constructivist and engineering models of instructional design," which is perceived in the Handbook as one of the four important developments in the last five years in educational communications and technology (see Chapter 56). The author believes that the analysis and evaluation of constructivist learning principles and constructivist instructional design reflect reality and are accurate.

The other four issues mentioned above (i.e., complexity theory, situativity instructional strategies, first principles of instruction and the 4C/ID model, and arguments on the future of educational technology triggered by changes in the trends of the technology research) are also focal components of educational communications and technology. They are innovative theories and applications that have had great impact on education and training.

At the same time, the author has also found that the Handbook contains differences and even bias in academic standpoints due to its large team of authors of different backgrounds. Some discussions are one-sided or even contain obvious mistakes. To avoid misleading and having adverse effects on the development of educational technology in China, this author would like to express personal views on the shortcomings of this Handbook, which will add to the five issues mentioned above to form the sixth issue: Analysing the Main Shortcomings of the $3^{\text {rd }}$ edition of Handbook of Research on Educational Communications and Technology.

Thus, the author's reflections on the Handbook will focus on the six issues mentioned above. The next section will analyse the first issue: constructivist learning principles and constructivist instructional design. Discussions on the remaining five issues will be published in two separate articles at a later time.

\section{A Deeper Understanding of "Constructivist Learning Principles"}

In regard to a deeper understanding of constructivist learning principles, after quoting the research by Kirschner et al. (2006), the last chapter (Chapter 56) of the Handbook points out that "the limitations of constructivist learning principles, such as discovery methods and inquiry learning, are becoming more clear" (p. 810). As this new finding has practical implications to education and training, the Handbook discusses it as the first of two most important findings in educational communications and technology in the last five years.

Since the 1990s, along with the rapid development in information technology which features multimedia computers and network communications (especially the Internet), e-learning (i.e., digital or Web-based learning) supported by such technology has spread worldwide. The interactivity offered by multimedia computers promotes learners' interest in learning and places learners at the centre of their cognitive learning process. In addition, the various valuable features of network communications promote students' creative and collaborative spirit and skills. For example, the abundant online resources facilitate learners' self-learning, self-inquiry, and self-discovery, and support anywhere, anytime collaboration and sharing on a large scale. Ever since the 1990s, E-learning, an unprecedented way of learning, has been regarded as an optimal learning mode. Constructivist learning principles (e.g., discovery methods and inquiry learning), 
which provide a theoretical basis for this mode of learning, are naturally becoming the most highly advocated learning principles in the field of educational technology, and more broadly, in global education.

However, Kirschner et al. (2006), based on evidence from empirical studies in education and training over the years, postulate that constructivist learning principles are not a panacea to be administered in every situation, despite its certain facilitating effects on selflearning, self-inquiry, and self-discovery. This is because these learning principles advocate minimally guided instruction and require learners to learn science through doing science. The obvious adverse effect of these learning principles has been proven in practice. So have the limitations of these principles (including constructivist instructional paradigms based on these principles). The following three limitations are discussed by Kirschner et al. (2006).

\subsection{The Constructivist Instructional Approach Characterized by "Minimally Guided Instruction” has Failed.}

Kirschner et al. (2006) argue that those instructional paradigms based on constructivist learning principles can neither be successfully applied in classroom teaching, nor can they provide an accurate understanding of human cognitive architecture. The human cognitive architecture emphasized here by Kirschner et al. (2006) is based on the theory of information processing. This theory maintains that human working memory is limited and serves as a gateway to information stored in long-term memory. With this understanding of the information processing theory, Kirschner et al. (2006) believe that learners, especially novice learners, due to the limitation of working memory, cannot effectively process information. As a result, their learning can be affected. They further point out that minimally guided instruction can overload the working memory of novice learners because "minimally guided instruction appears to proceed with no reference to the characteristics of working memory, long-term memory, or the intricate relations between them" (p.76). On the basis of their analysis of teaching and research case studies, they conclude that the failure of constructivist learning principles lies precisely in the paradigm of minimally guided instruction to novice learners.

\subsection{Learners do not Possess the Knowledge and Skill Base for Learning Science through Scientists' "doing Science”}

When discussing discovery learning principles in constructivism (especially the emphasis on learning science through "doing science"), Kirschner et al. (2006) postulate that children are different from adult experts in many ways. For example, children are not cognitively as powerful as adult experts, and they do not possess sufficient content and situated knowledge. According to Kirschner et al, situated knowledge refers to knowledge relating to conditions for the application of certain procedures or conditions for fast tracking certain knowledge. If children are required to learn science as scientists do, they must possess all the knowledge and capabilities. Without the knowledge and capabilities, they would be learning under a deficit model that will lead to failure.

\subsection{Under Certain Circumstances, Conventional Direct Instruction can be Superior to Constructivist Instruction}

Kirschner et al. (2006) regard learning as the change of long-term memory. Consequently, they assert that the architecture of long-term memory "provides us with the ultimate justification for instruction" (p.77). This was followed by a theoretical 
justification of the facilitation of longterm memory through conventional direct instruction based on a systems theory. They argue that such facilitation is superior to constructivist instruction.

\section{A Re-appraisal of the Relationship between Constructivist and Engineering Instructional Design}

As discussed above, "significant reduction in the gap and tension between constructivist and engineering models of instructional design" was held as one of the four important developments in educational communications and technology in the last five years. This is because constructivist learning principles (e.g., discovery and inquiry learning) has long been regarded as incompatible to conventional instruction based on a systems approach (also known as "direct instruction"). They often oppose each other in design and learning support. The other three are major changes in instructional strategies and learning technologies in e-learning, advances in using technology to optimize affective responses, and the shift from instructional model building to instructional model testing.

However, in recent years, research and practice in instructional models and instructional system design and development have demonstrated that instructional design based on constructive learning principles (e.g., constructivist instructional design) and conventional instructional design based on systems theories do not necessarily contradict each other. On the contrary, they can be very well-aligned to each other, so as to complement one another and maximize the advantages of each. This would help achieve the most effective integration between information technology and curriculum in e-learning. The following three classical case studies and their outstanding achievements best exemplify the results of the vigorous debates, the open dialogues, and mutual absorption between the two opposing viewpoints.

\subsection{The Debates on "Minimal Instructional Guidance" and the Consensus Reached}

Kirschner et al. (2006) contend that our understanding of human cognitive structure is based on the information processing theory that postulates that human working memory is limited, and that "minimally guided instruction appears to proceed with no reference to the characteristics of working memory, long-term memory, or the intricate relations between them" (p.76). Jonassen (2004), an advocate of contemporary radical constructivism, commented on these two contentions by saying that the cognitive structure discussed by Kirschner et al. only focused on working memory and long-term memory, while ignoring other aspects of cognitive structure. In fact, human cognitive structure should take into account the learning context, the learner, and the cognitive process (social cognitive process) in order to interpret and predict cognitive activities.

In the same line, Wise and O'Neill (2009) further argue that experimental studies on how to control the quantity of guidance cannot provide a valid basis for making assumptions about the fundamental merits of constructivist teaching. Although there are numerous debates on more-versus-less or high-versus-low guidance to learners, through the investigation of relevant research, especially instructional case studies, they have discovered that the quantity of guidance is just one dimension to achieve learning goals. Further, this dimension should be considered together with other dimensions to effectively achieve learning goals. For example, the context and timing of guidance are two other dimensions that should receive attention. 
At the same time, Gresalfi and Lester (2009) also point out that the difference between constructivism and conventional instruction does not lie in the quantity of guidance but in the types of guidance. They claim to have included in their instructional guidance various types of guidance suitable for the understanding of knowledge points through inquiring, explaining, and testing.

When discussing the misunderstanding of constructivist no-guided instruction or minimally guided instruction, Pea (2004) presents a persuasive account on the characteristics of scaffolding instructional strategy. He maintains that there are two characteristics that distinguish scaffolding from conventional instruction. First, conventional instruction only provides guidance when learners run into learning difficulties and are unable to proceed. In contrast, scaffolding provides learners with support to pursue learning independently. Second, after the learning content and learners are determined, in conventional instruction, the quantity and intensity of guidance remain unchanged, whereas in scaffolding instruction, the quantity and intensity of guidance tend to reduce or even fade, along with learners' increased mastery of knowledge and skills.

Despite the originally opposing views, consensus was reached on the two following aspects, as the result of the debates on minimally guided instruction:

1. In regard to human cognitive structure In addition to working memory and longterm memory, we should also take into account the learning context and learners' cognitive processes.

2. In regard to the effectiveness of instructional guidance - To effectively achieve learning goals, apart from the quantity dimension of guidance, we need to take into consideration other dimensions such as the context, the amount of time, the types of guidance, and the learners' abilities and needs.

\subsection{A Deeper Understanding of the Debates on "Using Scientists' doing Science Approach to Learn Science”}

Duschl and Duncan (2009), strong supporters of constructivism, disagree with the contention by Kirschner et al. (2006) that students should not be required to learn science through "doing science." They were not convinced by the argument put forward by Kirschner et al. that "students do not possess the necessary knowledge and cognitive ability" and that "students should not use a deficit model to learn science." They argue that Kirschner et al. do not understand that no age-related developmental stage will prevent students from learning science. They believe that more research should be done in relation to the development of children's cognitive ability. Learning science should not be simply regarded as the accumulation of knowledge in long-term memory. On the contrary, it is a cognitive development process that promotes conceptual changes and re-organization in memory. At the same time, through their own teaching experiences, they also point out that when scientific content becomes extremely abstract or complicated, the carefully designed curriculum using a systems approach and the provision of instructional guidance during discovery learning, will effectively help students to understand abstract scientific concepts, to grasp data models, and to develop and modify interpretations. They can also engage in-depth discussions on conceptual structures. In other words, to Duschl and Duncan (2009), appropriate instructional guidance based on a systems approach and studying science through scientists' doing science (e.g., discovery method) does not 
necessarily contradict each other. On the contrary, they can complement each other as conventional instructional guidance can help address the inadequacy of constructivist instructional paradigm.

\subsection{The Debates on and Comparison between "Direct Instruction" and Constructivist Instruction}

Some scholars such as Spiro and DeSchryver (2009) admit that conventional direct instruction can be more effective in well-structured domains such as mathematics and physics, while constructivist instruction (e.g., learning science through doing, discovery and inquiry learning including problem-based inquiry, context-based inquiry, project-based inquiry, resource-based inquiry) can lead to better results in ill-structured domains (e.g., medical diagnosis).

Herman and Gomez (2009) also state that some critics of constructivist instruction ignore some of the critical components of the instructional process such as motivation, the social context of the classroom, and other aspects of the dynamics of instruction. In addition, as argued above by Duschl and Duncan (2009), systems-based conventional instruction and science learning through "doing science" does not necessarily contradict each other. Research and case studies conducted by Gresalfi and Lester (2009) demonstrate that the constructivist instruction that they have advocated, explicitly includes many systems-based conventional instructional paradigms as inquiry, explanation, and testing. These paradigms are considered suitable for promoting learners' understanding of specific knowledge points. This clearly shows that new constructivist instruction does not reject teacher explanations at all. What it opposes is an entire lecture which is completely teacher-controlled. The constructivist paradigm does not oppose "direct instruction" with a systems approach.

\section{Concluding Remarks}

In the $21^{\text {st }}$ century, especially since 2004 , there have been intense debates and open dialogues in regard to the two opposing views discussed above in the field of educational communications and technology in the US. They have advanced understanding in the following two aspects:

1. Constructivist learning principles characterized by discovery and inquiry learning do possess their own uniqueness and unreplaceable advantages, but they are not perfectly optimal learning principles as shown by the three limitations critiqued by Kirschner et al. (2006).

2. Instructional design based on constructivist learning principles (e.g., constructivist instructional design) and conventional instruction based on a systems approach (e.g., engineering instructional design) are not in complete opposition. On the contrary, in many cases, they can be effectively brought together in a complementary manner to maximise their respective advantages. This has been convincingly testified by the intense debates on minimally guided instruction, the approach of learning science through doing science, direct instruction, and constructivist instruction, which have led to mutual absorption, acceptance, and valuable consensus.

In view of the above understanding, the Handbook lists understanding of the limitations of constructivist learning principles as first of two important findings in educational communications and technology in the last five years. For the same reason, the "significant reduction in the gap and tension between constructivist and engineering models of instructional design," was also deemed by the Handbook as one of the four 
important developments in educational communications and technology in the last five years. The author believes that such analysis, judgement, and evaluation in the Handbook reflect reality and are also appropriate, and will provide significant guidance to the development of theory and practice in educational communications and technology worldwide (i.e., in the field of international educational technology).

\section{Reference}

David H. Jonassen (ed.) (1996). Handbook of Research for Educational Communications and Technology. from http://aectorg.yourwebhosting.com/ edtech/ed1/firstedition.asp.

David H. Jonassen (ed.) (2004). "Handbook of Research on Educational Communications and Technology (Second Edition)". Lawrence Erlbaum Associates published.

J.Michael, M.David Merrill,Jeroen van Merriënboer and Marcy P.Driscoll (ed.) (2008). "Handbook of Research on Educational Communications and Technology (Third Edition)'”. Lawrence Erlbaum Associates published.

Jiao Jianli, Zhan Chunqing, He Qiulin. (2010a). Educational communications and technology's three research method issues_-Regarding the "Handbook of Research on Educational Communication and Technology (Third Edition)" sixth part's introduction and comment. Journal of Distance Education, 6, 23- 28.

Jiao Jianli, He Qiulin, Zhan Chunqing.(2010b). Learning models and its application Regarding the "Handbook of Research on Educational Communication and Technology (Third Edition)" fourth part's introduction and comment. Journal of Distance Education, 4 , 41- 46.

Kang Cui, Ma Xiaoling, Ju Huimin, Liu Meifeng.(2010). Design and development: education technology research and practice's the chiefly category Regarding the "Handbook of Research on Educational Communication and Technology (Third Edition)" fifth part's introduction and comment. Journal of Distance Education, 5 , 34-41.

Kirschner P. A., Sweller J. \& Clark R. E. (2006). Why minimal guidance during instruction does not work: An analysis of the failure of constructivist, discovery, problem-based, experiential, and inquirybased teaching. Educational Psychologist, $46(2), 75-86$.

Pea R. (2004). The social and technologic dimensions of scaffolding and related theoretical concepts for learning, education, and human activity. The Journal of the Learning Sciences, 13(3), 423-445.

Ren Youqun, Jiao Jianli, Liu Meifeng, and Wang Qiong. etc.( 2011). "Chinese translation: Handbook of Research on Educational Communications and Technology (Third Edition)"[M]. translation from "Handbook of Research on Educational Communications and Technology (Third Edition)". Shanghai : East China normal university press.

Sigmund Tobias, Thomas M. Duffy. (2009). Constructivist instruction: success or failure. New York: Routledge.

Wang Qiong.( 2010). Under the "educational communications and technology" viewing angle of teaching strategies research Regarding the "Handbook of Research on Educational Communication and Technology (Third Edition) "second part's introduction and comment. Journal of Distance Education, 2 , 29- 34.

Zhao Jian.(2010). Toward further integration of research on learning, cognition and technology_-Regarding the "Handbook of Research on Educational Communication and Technology (Third 
Handbook of Research on Educational Communications and Technology (3rd Ed) Some Reflections (1): On a Deeper Understanding of the Constructivist Learning Principles and Constructivist Instructional Design

Edition)" third part's introduction and comment. Journal of Distance Education, 3, 30- 36.

Zheng Tainian, Ren Youqun.( 2010).

Educational communications and technology of research foundation Regarding the "Handbook of Research on Educational Communication and Technology (Third Edition)" first part's introduction and comment. Journal of Distance Education, 1, 18- 24. 